\title{
ESTETIKA ORNAMEN RUMOH ACEH LUBUK SUKON KECAMATAN INGIN JAYA KABUPATEN ACEH BESAR
}

\author{
Indra Maulana ${ }^{1^{*}}$, Ahmad Akmal ${ }^{2 *}$, Febri Yulika ${ }^{3^{*}}$ \\ Minat Pengkajian Seni Kriya Program Pascasarjana \\ Institut Seni Indonesia Padangpanjang \\ Jl. Bahder Johan, Guguak Malintang, Padangpanjang, Kota Padangpanjang, 27126. \\ Sumatera Barat. Indonesia. \\ Email: indrasamalanga@gmail.com
}

\begin{abstract}
Abstrak
Rumoh Aceh merupakan rumah tradisional milik masyarakat Aceh. Saat ini rumoh Aceh masih dijaga dan dirawat oleh masyarakat Aceh di Desa Lubuk Sukon Kecamatan Ingin Jaya Kabupaten Aceh Besar. Pada tahun 2012 Lubuk Sukon ditetapkan sebagai Desa Wisata oleh Dinas Pariwisata dan Kebudayaan Aceh untuk dijadikan sebagai objek wisata budaya. Rumoh Aceh merupakan rumah panggung dan dihiasi oleh berbagai ukiran ornamen yang mempunyai makna filosofi. Penelitian ini menggunakan metode kualitatif dan di analisis menggunakan pendekatan teori estetika dan teori motif untuk melihat keindahan bentuk dan pemaknaan ornamen rumoh Aceh. Ornamen yang terdapat pada rumoh Aceh merupakan ornamen hasil representasi dari bentuk flora terdiri dari bentuk motif bungong mawo, motif pucoek rebong, motif pucok labu, dan motif oen ranub. Bentuk fauna terdiri dari motif ayam. Bentuk kaligrafi terdiri dari motif tulisan Allah dan Laa Ilaha Illallah. Bentuk alam terdiri dari motif awan, motif bulan dan motif bintang. Bentuk alam benda terdiri motif kupiah meuketop, motif rante dan motif lungkandet serta motif geometris. Motif-motif tersebut memiliki makna filosofis sebagai kearifan lokal dari nilai budaya Aceh dalam mengatur kehidupan sosial masyarakat.
\end{abstract}

Kata Kunci: estetika, ornamen, rumoh Aceh

\begin{abstract}
Rumoh Aceh is a traditional house belongs to the people of Aceh. The current house is still maintained and cared for by the people of Aceh in the village of Lubuk Sukon Sub District Ingin Jaya Regency Aceh Besar. In the year 2012 Lubuk Sukon established as a Village by the cultural and Tourism Office of Aceh to serve as the cultural attractions. Rumoh Aceh is the home stage and decorated by various carved ornaments that have a meaning of philosophy. This study uses qualitative methods and analysis using the approach in the theory of aesthetics and theory of a motifs to see the beauty of the shape and definition of ornament rumoh Aceh. Ornament in the house It is the result of the representation of the form of the ornament flora consist of bungong mawo motif, pucoek rebong motif, pucok labu motif, and oen ranub motif. The form of fauna consists of a chicken motif. The forms of calligraphy consisting of motif writing Allah and Laa Ilaha Illallah. The form of naturals form consists of cloud motif, the motif of the Moon and stars motif. The forms natural objects composed kupiah meuketop motif, rante motif and lungkandet motif as well as geometric motif. These motifs have philosophical meaning as the local wisdom of Aceh cultural values in governs social life of society.
\end{abstract}

Keywords: aesthetica, ornament, rumoh Aceh

\section{PENDAHULUAN}

Rumah tempat tinggal bagi suku bangsa Aceh disebut dengan rumoh (Bakar et al., 1985). Rumah yang berbentuk bangunan tradisional Aceh disebut rumoh Aceh (Hadjad et al., 1984). Rumoh Aceh masih dapat dijumpai di Desa Lubuk Sukon Kecamatan Ingin Iaya Kabupaten Aceh Besar Provinsi Aceh. Rumoh Aceh yang ada di Desa Lubuk Sukon sebanyak $60 \%$ dari jumlah 191 rumah penduduk (Darzam, Irmayani \& Erliana, 2012).

Kondisi kehidupan budaya Desa Lubuk Sukon saat ini masih terlihat nilai-nilai kearifan lokal yang memiliki tata letak dan tata ruang desa serta menjaga nilai-nilai budaya tradisional masyarakat Aceh. Hal ini diterapkan untuk mempertahankan dan menyelamatkan kearifan lokal tradisional Aceh. 


\section{Gorga Jurnal Seni Rupa \\ Volume 07 Nomor 02 \\ p-ISSN: 2301-5942 | e-ISSN: 2580-2380}

Khususnya rumoh Aceh yang masih terlihat orisinalitas dari segi bentuk dan penerapan ornamen pada rumoh Aceh. Sehingga pada 15 Oktober 2012 Pemerintah Daerah Aceh melalui Dinas Pariwisata dan Kebudayaan Aceh menetapkan Desa Lubuk Sukon sebagai desa wisata untuk dijadikan sebagai cagar budaya dan objek wisata budaya (Darzam, et al., 2012 \& Meutia, et al., 2016).

Rumoh Aceh Adalah rumah berbentuk rumah panggung merupakan bangunan di atas tiang-tiang bundar yang terbuat dari batang-batang kayu kuat disebut tameh (Hadjad et al., 1984). Jumlah tiang tersebut ada 20 dan 24 buah yang besarnya lebih kurang 30 sentimeter garis menengahnya. Tinggi bangunan rumoh Aceh sampai batas lantai lebih kurang dua setengah meter, sedangkan tinggi keseluruhan bangunan rumoh Aceh lebih kurang lima meter. Bagian yang berada dibawah lantai merupakan kolong terbuka karena tidak diberi dinding. Bagian ruangan rumoh Aceh yang berada di atas tiang-tiang terbagi atas tiga ruangan, (1) ruangan depan (serambi depan) yang disebut seramoe keue (serambi depan), (2) ruang tengah yang disebut tengoh, dan (3) ruang belakang (serambi belakang) yang disebut seramoe likoet (Hasan, 2009 \& Majid et al., 2017).

Rumoh Aceh Lubuk Sukon pada setiap bagian dapat dijumpai ornamen. Karena suku bangsa Aceh pada hakekatnya termasuk suku yang mencintai seni, bahkan cenderung memiliki jiwa dan apresiasi seni yang tinggi (Herwandi, Ibrahim \& Yusdi, 2017). Ornamen pada rumoh Aceh diterapkan pada tolak angin, dinding, tangga, kindang dan balok penyangga atap.

Ornamen yang terdapat pada rumoh Aceh Lubuk Sukon mempunyai berbagai jenis bentuk motif yang berangkat dari lingkungan alam seperti; motif bentuk flora, motif bentuk fauna, motif bentuk kaligrafi Islam, motif bentuk alam, motif bentuk geometris dan motif bentuk alam benda (benda tradisional Aceh).

Ornamen pada rumoh Aceh Lubuk Sukon memiliki bentuk serta makna yang penting dan menarik untuk dikaji secara terperinci. Penelitian ini bertujuan untuk mengetahui bentuk dan pemaknaan yang terkandung pada ornamen rumoh Aceh terhadap masyarakat Lubuk Sukon. Hasil dari penelitian ornamen rumoh Aceh Lubuk Sukon agar dapat menajadi ilmu pengetahuan bagi masyarakat awam dan masyarakat umum. Terkait dengan kandungan nilai-nilai budaya Aceh yang terkandung dalam ornamen rumoh Aceh. Sehingga nantinya tetap terjaga dan terawat untuk membatasi pergeseran dan perubahan pada perkembangan zaman yang terus berubah. Hal ini juga tidak menutup kemungkinan untuk dapat di implementasikan pada bangunan masa kini dan bendabenda lainnya sebagai upaya pelestarian ornamen tradisional Aceh.

\section{KAJIAN TEORI}

Untuk mengetahui estetika ornamen rumoh Aceh Lubuk Sukon, sangat diperlukan kerangka teoritis. Digunaka sebagai pisau pembedah dalam menganalisis permasalahan. Hal ini menggunakan pendekatan teori estetika untuk mengurai bentuk dan pemaknaan ornamen rumoh Aceh Lubuk Sukon.

A.A.M Djelantik (2014: 15) mengatakan bahwa estetika adalah suatu ilmu yang mempelajari segala sesuatu yang berkaitan dengan keindahan, mempelajari dari segala aspek tentang kebenaran dari keindahan. Mengungkapkan secara umum, keindahan meliputi keindahan alam dan keindahan buatan manusia yang disebut karya seni atau kesenian. Dengan demikian karya dapat dikatakan merupakan salah satu wadah yang mengandung unsur-unsur keindahan. Unsur-unsur estetika dalam semua benda atau peristiwa mengandung tiga aspek dasar; (1) wujud atau rupa (appearance), (2) bobot atau isi (content, subtance), dan (3) penampilan, penyajian (presentation).

Teori lain yang digunakan yaitu teori motif, Dharsono Sony Kartika (2016:77-78) mengatakan bahwa seni sebagai tuntunan dan tontonan. Bentuk yang terdiri dari pengulangan pola yang terdiri dari kumpulan motif yang ditata dengan indah (tontonan), dan mempunyai makna filosofis (tuntunan hidup) pada motif utama. Bentuk adalah struktur atau komposisi, merupakan tata susun yang terdiri dari pengulangan atau susunan pola. Pola terdiri dari motif utama, motif pengisi (selingan), dan Motif isen (isian).

\section{METODE PENELITIAN}

Desa Lubuk Sukon memiliki luas wilayah $112 \mathrm{Ha}$ (Darzam, Irmayani \& Erliana, 2012: 7). Desa ini terletak di Kecamatan Ingin Jaya Kabupaten Aceh Besar. Desa Lubuk Sukon berbatasan dengan DesaDesa lainnya yaitu; sebelah Utara berbatasan dengan Desa Dham Pulo, sebelah Selatan berbatasan dengan Kecamatan Suka Makmur, Sebelah Timur berbatasan dengan Desa Lubuk Gapuy, dan sebelah Barat berbatasan dengan Desa Dham Ceukok. Darzam (2012: 7) mengatakan, secara administratif Desa Lubuk Sukon terbagi ke dalam empat dusun, yaitu 


\section{Gorga Jurnal Seni Rupa \\ Volume 07 Nomor 02 \\ p-ISSN: 2301-5942 | e-ISSN: 2580-2380}

Dusun Darussalihin, Dusun Darul Makmur, Dusun Darul Ulum dan Dusun Darussalam.

Rumah yang ada di Desa Lubuk Sukon didominasi oleh rumoh Aceh sebanyak 69 unit. Selain itu terdapat 58 unit rumoh santeut dan 64 unit rumoh batee (rumah modern). Rumah berkontruksi kayu mulai dibangun pada tahun 1950-1980. Sedangkan rumah yang tipologi beton dibangun pada tahun 1981-1990 (Darzam, Irmayani \& Erliana, 2012: 18).

Bila dilihat dari titik berdiri sebelah Barat atau sebelah Timur bentuk atapnya seperti segitiga, dengan tiang penyangga (tameh) berbentuk bulat, dengan diameter $15-20 \mathrm{~cm}$. Terdiri dari tiga bagian tiang yaitu tiang bagian depan, tiang bagian tengah dan tiang bagian belakang. Rumoh Aceh berbentuk rumah panggung bujur sangkar dengan tinggi tiang 2,5-3,2 $\mathrm{m}$ dari permukaan tanah. Sehingga ruang bawah menjadi kolong yang dapat digunakan sebagai ruang untuk berteduh, istirahat, dan tempat menyimpan barang hasil panen serta peralatan mata pencaharian. Selain itu juga berfungsi sebagai aktivitas secara umum seperti ruang untuk produksi bahan makanan, mengolah hasil pertanian, menghasilkan karya-karya keterampilan/kreativitas, melakukan aktivitas pertukangan dan melakukan transaksi (Wawancara, Nurdin AR, Banda Aceh, 28 Juni 2018).

Secara keseluruhan bentuk asli pola ruang rumoh Aceh di Desa Lubuk Sukon telah mengalami perubahan bentuk. Dewasa ini rumah tinggal di Desa Lubuk Sukon hanya tersisa \pm 40 rumah yang masih mempertahankan bentuk panggung dari rumoh Aceh. Namun hampir $99 \%$ dari 40 rumah telah mengalami perubahan dan penambahan pola ruang dari bentuk aslinya dan hanya 1 rumah yang masih mempertahankan keasliannya yang terdapat di Dusun Darussalihin. Adapun bentuk asli pola ruang rumoh Aceh di Desa Lubuk Sukon adalah sebagai berikut.

Ruang bagian dalam pada rumoh Aceh di Desa Lubuk Sukon dibagi kedalam 3 bagian utama, yaitu : a) Seuramoe keu (serambi depan), berfungsi sebagai tempat musyawarah, menerima tamu laki-laki, tempat belajar anak laki-laki, dan tempat tidur anak laki-laki, serta kepentingan umum lainnya. Disini disandarkan anak tangga yang biasanya berjumlah 5, 7 dan 9 (Darzam, 2012: 22 \& Yusuf, 2015). b) Seuramoe teungoh (serambi tengah), atau tungai, bersifat tertutup sesuai dengan fungsinya yaitu sebagai kamar tidur. Ukurannya lebih tinggi setengah meter dari serambi depan dan serambi belakang. Kamar sebelah barat ditempati oleh tuan rumah, dan kamar sebelah timur atau rumoh anjong yang terletak di sebelah
Timur di tempati oleh anak perempuan (Darzam, et al., 2012 \& Yusuf, 2015). c) Seuramoe likoet (Serambi belakang), merupakan ruang dapur dan aktivitas untuk kaum perempuan. (Darzam, et al, 2012 \& Yusuf, 2015).

Rumoh Aceh memiliki keunikan tersendiri dari segi bentuk arsitekturnya. Memiliki bentuk dan fungsi dari ruang-ruang yang memberikan arti khusus bagi masyarakat Aceh di Desa Lubuk Sukon dan mayarakat Aceh pada umumnya. Begitu juga halnya dengan ornamen yang menghiasi bidang-bidang rumoh Aceh. Memiliki keindahan dari segi bentuk dan arti tersendiri bagi pemilik rumoh Aceh. Penerapan ornamen pada rumoh Aceh Lubuk Sukon diukir oleh tukang yang disebut utoh. Pada perkembangan zaman yang semakin berkembang, ornamen pada rumoh Aceh sudah jarang di jumpai. Begitu juga halnya pada rumah modern yang ada di Desa Lubuk Sukon maupun secara umumnya tidak ada penerapan ornamen tradisional Aceh pada setiap bagiannya.

Hasil penelitian dan pengamatan serta hasil wawancara dengan narasumber di Desa Lubuk Sukon. Terkait dengan objek penelitian estetika ornamen rumoh Aceh Lubuk Sukon. Hanya menemukan lima rumoh Aceh yang masih dihiasi oleh ornamen. Ornamen pada rumoh Aceh terdapat pada dinding, tolak angin, tangga, kindang dan balok peyangga atap. Ornamen yang diterapkan berbentuk motif flora, bentuk motif fauna, bentuk motif kaligrafi Islam, bentuk motif alam, bentuk motif geometris dan bentuk motif alam benda (benda tradisional Aceh).

\section{HASIL DAN PEMBAHASAN}

Tabel 1.

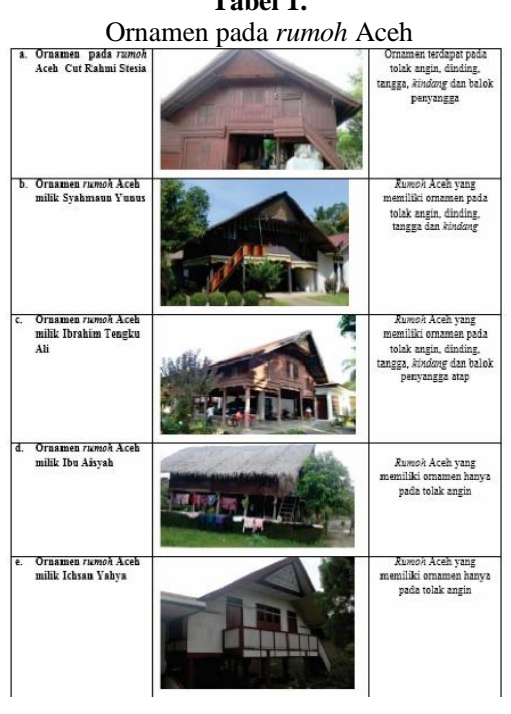




\section{Gorga Jurnal Seni Rupa \\ Volume 07 Nomor 02 \\ p-ISSN: 2301-5942 | e-ISSN: 2580-2380}

akan menimbulkan rasa-nikmat indah dalam diri sesorang.

Menurut Djelantik, (2004: 14) di dalam rasa-nikmat indah yang ada pada diri manusia tentu pasti menimbulkan pertanyaan apa yang terkandung, dari berbagai macam kesenian yang ada sehingga memunculkan rasa nikmat indah. Jawaban dari berbagai pertanyaan tersebut tidak dapat di peroleh secara langsung. Namun jalan tersebut dapat ditempuh melalui pengetahuan mengenai ciri-ciri barang yang menimbulkan rasa nikmat dan indah itu. Kita dapat menyusun berbagai ciri khas dari barang kesenian melalui pengamatan dan penyelidikan. Penyelidikan dan pengamatan barang seni tentunya tidak cukup hanya satu barang kesenian, tetapi malalui banyak kesenian. Berdasarkan dari hal tersebut kemudian di petik kesamaan yang paling sering dijumpai dan akhirnya dapat ditarik kesimpulan.

Ciri-ciri yang berperan dalam perangsangan rasa indah dapat disebut ciri estetik yang hadir dalam perwujudan karya seni. Potensi untuk menstimulus rasa indah dalam diri manusia dengan mengamati dan menyelidiki benda kesenian itulah maka diperlukan sifat-sifat yang dikenal dengan unsur estetik. Benda atau peristiwa kesenian semuanya mengandung unsurunsur estetika. Dimana unsur tersebut terbagi menjadi tiga, yakni; 1) Segala hal dalam kesenian yang dapat terlihat oleh mata (visual) maupun yang dapat didengar oleh telinga (akustis) dapat dinyatakan sebagai wujud. Aspek wujud dibagi menjadi dua yakni; bentuk (form) dan struktur (structure). Bentuk meliputi titik, garis, bidang, dan gempal (volume). Sedangkan struktur meliputi, keutuhan atau kebersatuan (unity), penojolan atau penekanan, dan keseimbangan (balance). 2) Suatu karya seni atau peristiwa kesenian tidak semata-mata yang hanya dilihat. Namun juga meliputi apa yang dirasakan yang dihayati sebagai makna dari wujud kesenian tersebut. Tiga aspek bobot kesenian adalah suasana (mood), gagasan (ide), ibarat atau pesan (message). 3) Penampilan mengacu pada pengertian bagaimana cara kesenian itu disajikan dan disuguhkan kepada penikmatnya. Unsur penyajian terbagi menjadi tiga, yakni: bakat (talent), ketrampilan (skill), dan sarana atau media. Berikut ini adalah analisis kajian estetika ornamen rumoh Aceh Lubuk Sukon berdasarkan teori estetika Djelantik.

diwujudkan oleh manusia. Hal ini untuk memberi rasa ketenangan dan kepuasan dengan pencapaian rasa indah, termasuk di dalamnya barang-barang hasil kerajinan tangan, lukisan, patung, musik, nyanyian, dan lain sebagainya. Hasil dari unsur seni tersebut tentu tidak hanya kita lihat dan kita dengar, namun

\section{KESIMPULAN DAN SARAN} merupakan media sebagai ungkapan perasaan. Diwujudkan dalam bentuk visual dan dapat berperan
Ornamen hadir ditengah-tengah masyarakat 


\section{Gorga Jurnal Seni Rupa \\ Volume 07 Nomor 02 \\ p-ISSN: 2301-5942 | e-ISSN: 2580-2380}

dalam pengembangan pemikiran-pemikiran masa lampau yang pernah adap pada senimanya. Ornamen juga diciptakan untuk mengungkapkan dan menyampaikan makna filosofis budaya dari suatu daerah melalui simbol-simbol yang memiliki maksud dan tujuan tertentu yang bermakna.

Tradisi dan budaya di Aceh tidaklah surut dari pemikiran filosofis. Semua isi pemikiran tersebut diterjemahkan ke dalam karya-karya bahasa Aceh dan Melayu. Demikian pula halnya dengan simbol-simbol yang merupakan dialektika pemikir Aceh juga terlihat dari hasil karya kreasi seni ornamen pada rumoh Aceh Lubuk Sukon (Bustamam-Ahmad, 2016: 117). Oleh karena itu, setiap karya seni pasti memiliki maksud dan tujuan dari apa yang dibentuk oleh seniman. Tentu akan memberikan sebuah keterangan dari keadaan lingkungan yang pernah ada pada suatu daerah. Sehingga menjadi inspirasi yang bermakna bagi seniman. Setiap perwujudan ornamen atau bentukbentuk motif tentu melalui kesepakatan bersama dari suatu komunitas sebelum mewujudkannya pada sebuah media. Seperti, berupa bangunan tempat tinggal, bangunan tempat ibadah, alat-alat teknologi, senjata, dan pakaian adat.

Setiap motif-motif yang diterapkan tidak serta merta dihadirkan begitu saja tentu memiliki maksud dan tujuan, baik itu dari segi bentuk ataupun makna. Hal itu juga bedasarkan kesepakan bersama pula yang terjadi pada masa perwujudannya. Masa demi masa terus berlalu, waktu demi waktu terus terlewati, zaman terus berubah. Tidak banyak masyarakat yang mengetahui akan makna-makna dari setiap bentuk motif yang diterapkan pada rumoh Aceh sebagai bangunan masa lampau. Oleh sebab itu, perlu kiranya menuliskan atau membuat kembali makna-makna pada setiap bentuk motif yang ada pada rumoh Aceh. Hal ini perlu dilakukan melalui pencarian-pencarian dari berbagai narasumber yang mengerti dan faham terkait bentuk dan makna dari setiap motif-motif yang diterapkan. Bertujuan untuk menggali ilmu-ilmu tentang bentuk dan makna motif yang ada pada masyarakat Aceh (ilmu tentang Aceh). Tentu saja ini berkaitan erat dengan kosmologi dan kearifan yang ada di Aceh. Karena setiap manusia memiliki filosofi hidup bahkan dapat dikatakan sebagai filosofis atau filosofer. Manusia yang beragama selalu menjabarkan relasi antara manusia, alam dan Tuhan. Hal ini juga berlaku dalam tradisi akademisi seni yang tidak boleh surut akan pemikiran-pemikiran filosofis, untuk memikirkan makna-makna dari setiap bentuk motif pada rumoh Aceh dan benda-benda rupa lainnya yang ada pada masa lalu dan akan datang.
Seni (art) merupakan salah satu unsur kebudayaan universal karena kepekaan rasa dari seorang seniman berpengaruh dalam melahirkan karya seni yang berkarakter. Hal ini akhirnya dapat menentukan posisi sebuah karya seni yang diikuti oleh penikmat seni meskipun memiliki selera dan cita rasa estetis berbeda satu sama lain. Didukung oleh niat dan pengabdian yang tulus, maka tujuan dan fungsi karya seni menjadi pengawal dalam proses kreatif penciptaannya. Saifullah \& Febri Yulika (2012: 25) menerangkan:

Kesenian dikenali sebagai art dalam bahasa Inggris dan Al-fan dalam bahasa Arab. Ia membawa makna halus, cantik, indah, kudus, suci-bersih, seronokgembira, harmonis, tersusun sistematik, lembut, sejuk, segar, merangsang, lapang, nyaman, kejiwaan dan kedalaman.

Seni sebagai kreasi perjalanan sejarah umat manusia lahir dari simbol, sejumlah gagasan, ide, imajinasi, atas responnya terhadap alam sekitar yang diolah oleh seniman. Seorang seniman tidak hanya berkarya sebagai abdi alam sekitarnya, tetapi seniman juga mencari makna dirinya dan mempunyai arti yang dapat dipertanggung jawabkan kepada sesamanya. Artinya, ketika manusia melahirkan batin pada bendabenda alamiah disekelilingnya, maka batinnya semakin terbuka.

Seni merupakan cerminan budaya dan kehidupan masyarakat. Kita dapat mengetahui tentang suatu kaum dan masyarakat melalui kesenian mareka. Kebudayaan sesebuah masyarakat hasil daripada gaya hidup akan memantulkan hasil kesenian mareka. Ia berkait rapat dengan dengan kepercayaan, emosi dan pengalaman yang dijelmakan dalam bentuk karya. Ini dapat jelas dilihat dalam bentuk kesenian yang terdapat dalam sebuah kaum di setiap daerah di Indonesia. Melalui hasil kerajinan tangan, pertukangan, seni hiburan dan sebagainya. Seni dalam berbagai bentuk itu tidak terpisah-pisah dari karena ia wujud dalam kesatuan yang harmonis yang dapat membayangkan ketinggian dan keikhlasan budi, ketinggian daya fikir dan intelektual serta kemurnian nilai suatu bangsa. Kecenderungan dalam bidang kesenian bukanlah sesuatu yang dibuat-buat bahkan ia merupakan curahan daripada benak hati sesuatu masyarakat lantaran suatu falsafah yang mareka anuti telah menjadi sepadu dengan hati dan jiwa mareka. Hal ini menjadi tidak heran dengan meneliti hasil kesenian sebuah masyarakat, kita dapat mengetahui kecenderungan suatu masyarakat (Saifullah \&Yulika, 2012: 25-26). 


\section{Gorga Jurnal Seni Rupa \\ Volume 07 Nomor 02 \\ p-ISSN: 2301-5942 | e-ISSN: 2580-2380}

Sebagaimana diketahui bahwa proses pembuatan ornamen pada rumoh Aceh tidak hanya berangkat dari ruang kosong belaka. Kalau selama ini banyak yang beranggapan bahwa ornamen rumoh Aceh hanyalah merupakan sebagai hiasan ukiran di atas kayu semata. Tanpa memiliki makna apapun atau makna khusus.

Makna khusus yaitu kata atau istilah yang pemakaiannya atau maknanya terbatas pada suatu bidang tertentu. Secara khusus pula digunakan untuk memberikan istilah pada bidang tertentu agar semakin jelas (Anton, 1990: 548). Maka pemikiran semacam ini salah dan perlu diluruskan kembali. Sedangkan setiap rangkaian ornamen atau ukiran pada rumoh Aceh memiliki makna filosofis dari bentuk simbolis tertentu, tergantung siapa dan apa tujuan dari pemiliknya, baik secara individu, sosial serta fisiknya.

Bentuk ornamen pada rumoh Aceh Lubuk Sukon tersebut, sangat erat kaitannya dengan lingkungan sekitar dilihat dari letak dan keadaan Desa Lubuk Sukon yang banyak terdapat tumbuh-tumbuhan, binatang peliharaan (ayam) dan berdekatan dengan sungai dan memiliki makna filosofis tersendiri. Makna yang ada pada setiap bentuk motif juga tidak terlepas dari pengalaman hidup masyarakat yang selalu berhubungan dengan alam sekitar. Sehingga setiap motif yang diterapkan memiliki maksud dan tujuan tertentu sebagai pedoman dalam menjalankan kehidupan sehari-hari. Oleh karena itu, makna-makna bentuk motif tersebut perlu diuraikan secara terperinci agar dapat difahami dan menjadi pengetahuan bagi masyarakat umum. Agar tidak mengabaikan apa yang sudah diciptakan oleh orang-orang terdahulu. Sebagai masyarakat yang memiliki peradaban dan kebudayaan untuk dapat dinikmati oleh generasi penerusnya.

Motif pada rumoh Aceh merupakan motif yang terdiri dari beberapa kontruksi motif. Unsur motif merupakan perpaduan dari motif pokok atau motif utama, motif pendukung atau motif selingan yang memperkuat keseimbangan komposisi dalam susunan ornamen dan motif isen yang memberikan nilai keindahan pada ornamen rumoh Aceh. Motif yang ada pada rumoh Aceh terdiri atas elemen-elemen yang dapat dikelompokkan menjadi ornamen utama, ornamen pengisi dan isen.

Motif utama adalah gambaran pokok yang merupakan inti dari motif tersebut. Motif pengisi atau selingan digunakan untuk sebagai pengisi bidang untuk memperindah motif secara keseluruhan. Motif ini berukuran lebih kecil dan berbentuk lebih sederhana dibanding motif pokok. Contoh motif pengisi adalah motif berbentuk daun, tangkai, dan kuncup. Motif isen merupakan motif yang berfungsi sebagai pengisi atau pelengkap ornamen dan isen digunakan untuk meperindah pola secara keseluruhan. Isen merupakan penggamabaran dengan bentuk tertentu yang digunakan untuk mengisi atau pengisi motif. Berbentuk kecil dan sederhana misalnya berupa titiktitik yang masih ada dan berkembang hingga saat ini seperti yang sering digunakan pada batik.

\section{DAFTAR RUJUKAN}

Bakar, A. et al. (1985) Kamus Aceh Indonesia 2. Jakarta: Pusat Pembina dan Pengembangan Bahasa.

Bustamam-Ahmad, K. (2016) Acehnologi (Volume 1). Banda Aceh: Bandar Publishing.

Darzam, Irmayani and Erliana (2012) Profil Desa Wisata Lubuk Sukon. Edited by N. AR. Banda Aceh: Dinas Kebudayaan Dan Pariwisata Aceh.

Denzin, N. K. and Lincoln, Y. S. (2009) Qualitative Reseach. Yogyakarta: Pustaka Pelajar.

Djelantik, A. A. . (2004) Estetika Sebuah Pengantar Cetakan Ke-3. Bandung: MSPI \& Arti.

Hadjad, A. et al. (1984) Arsitektur Tradisional Propinsi Daerah Istimewa Aceh. Banda Aceh: Pusat Penelitian Sejarah Dan Budaya Proyek Inventarisasi Dan Dokumentasi Kebudayaan Daerah.

Hasan, I. (2009) Architecture and the Politics of Identity in Indonesia A Study of the Cultural History of Aceh. The University of Adelaide School.

Herwandi, Ibrahim, H. and Yusdi, M. (2017) 'Karakter Lokal Pada Artefak Seni Makam Berhias di Nanggroe Aceh Darussalam (Abad 13-18 M) 1', 2.

Majid, N. H. A. et al. (2017) 'Sustainability concepts in Malay and aceh traditional houses', Journal of the Malaysian Institute of Planners, 15(January), pp. 1-12. doi: 10.21837/pmjournal.v15.i6.216.

Meutia, E., Sari, L. H. \& Irwansyah, M. (2016) Menggali Nilai-Nilai Arsitektur Berkelanjutan di Gampong Lubuk Sukun Aceh Besar, Seminar Nasional Sains dan Teknologi Lingkungan II. Padang. Available at:

lingkungan.ft.unand.ac.id/images/fileTL/SNS TL_II/OP_006.pdf.

Moliono, A. M. (1990) Kamus Besar Bahasa Indonesia cetakan ke-3. Jakarta: Departemen Pendidikan dan Kebudayaan dengan Balai 


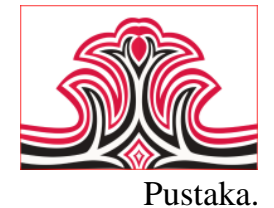

Rohidi, T. R. (2011) Metodologi Penelitian Seni. Semarang: CIpta Prima Nusantara.

Saifullah and Yulika, F. (2012) Sejarah Perkembangan Seni dan Kesenian Dalam Islam. Padangpanjang: ISI Padangpanjang \& Creatif Production Padang.

Soedarso, S. (2006) Trilogi seni Penciptaan Eksistensi Dan Kegunaan Seni. Yogyakarta: BP ISI Yogyakarta.

Suryajaya, M. (2016) Sejarah Estetika. Jakarta: Gang Kabel.

Yulika, F. (2016) Jejak Seni Dalam Sejarah Islam. Padangpanjang: ISI Padangpanjang.

Yusuf, J. (2015) Rumah Tradisional Etnis-Etnis Di Aceh. Banda Aceh: Dinas Kebudayaan Dan Pariwisata Aceh. 